\title{
Phase I study of enzastaurin and bevacizumab in patients with advanced cancer: safety, efficacy and pharmacokinetics
}

\author{
Nwabundo Nwankwo - Zhe Zhang • Ting Wang • \\ Connie Collins • Lee Resta $\cdot$ Sabine Ermisch • \\ Jeannette Day • Rodney Decker • Lori Kornberg • \\ Steven Nicol • Donald Thornton • \\ Deborah K. Armstrong • Michael A. Carducci
}

Received: 9 March 2012 / Accepted: 22 June 2012 /Published online: 6 July 2012

(C) The Author(s) 2012. This article is published with open access at Springerlink.com

Summary Purpose Given distinct mechanism of actions of enzastaurin and bevacizumab, preclinical studies suggest enhanced antitumor activity in combination. This phase I study assessed the combination's safety and efficacy. Patients and methods Six advanced cancer patients could be enrolled in each of 11 cohorts. Patients received an enzastaurin loading dose. Oral enzastaurin (500 $\mathrm{mg}$ once daily [QD], $250 \mathrm{mg}$ twice daily [BID], $375 \mathrm{mg}$ BID, $500 \mathrm{mg}$ BID, and $750 \mathrm{mg} \mathrm{BID}$ ) was

The content was presented in part at the: Ovarian Cancer Research Symposium (Rivken Conference), 2008; $44^{\text {th }}$ Annual Meeting of the American Society of Clinical Oncology, 2008; $45^{\text {th }}$ Annual Meeting of the American Society of Clinical Oncology, 2009; 41st Annual Meeting of the Society of Gynecologic Oncologists, 2010.

\section{ClinicalTrials.Gov: NCT00550927}

Electronic supplementary material The online version of this article (doi:10.1007/s10637-012-9850-6) contains supplementary material, which is available to authorized users.

N. Nwankwo $\cdot$ Z. Zhang $\cdot$ T. Wang $\cdot$ C. Collins $\cdot$ L. Resta

D. K. Armstrong

Kimmel Cancer Center at Johns Hopkins,

Baltimore, MD, USA

S. Ermisch $\cdot$ R. Decker $\cdot$ S. Nicol $\cdot$ D. Thornton

Eli Lilly and Company,

Indianapolis, IN, USA

J. Day $\cdot$ L. Kornberg

PharmaNet/i3, an inVentiv Health company,

Princeton, NJ, USA

M. A. Carducci $(\square)$

Chemical Therapeutics Program,

Kimmel Cancer Center at Johns Hopkins,

CRB 1 M59, 1650 Orleans Street,

Baltimore, MD 21231-1000, USA

e-mail: carducci@jhmi.edu escalated in each cohort in combination with bevacizumab dosed at $5 \mathrm{mg} / \mathrm{kg}$ every 2 weeks, $10 \mathrm{mg} / \mathrm{kg}$ every 2 weeks, or $15 \mathrm{mg} / \mathrm{kg}$ every 3 weeks until a dose-limiting toxicity (DLT) occurred in 2 of 6 patients in any cohort. Results Sixty-seven patients (31, ovarian cancer [ovcar]) were evaluable for safety and efficacy. Six treatment-related DLTs occurred: grade 3 fatigue $(n=4)$, grade 4 cerebral hemorrhage, and grade 3 elevated aspartate transaminase. Common drug-related toxicities included change in color of urine and stool, fatigue, pain, diarrhea, and nausea. The maximum tolerated dose of enzastaurin was $750 \mathrm{mg}$ BID in combination with any tested bevacizumab dose/schedule. Overall response rate was $19.4 \%$ ( $32.3 \%$ ovcar). Median time to progression was 3.7 months (95\% confidence interval [CI], 2.7-5.5), with 8.3 months (95\% CI, 3.7-11.1) in ovcar. Overall, $35.9 \%$ (50.4 \% ovcar) of patients remained without disease progression after 6 months. Conclusion The recommended phase II doses of enzastaurin were $500 \mathrm{mg}$ QD up to $500 \mathrm{mg}$ BID with any tested dose/schedule of bevacizumab. This combination demonstrated encouraging clinical activity, particularly in ovcar.

Keywords Enzastaurin · Bevacizumab · Phase I · Advanced cancer $\cdot$ Ovarian cancer

\section{Introduction}

Enzastaurin HCL (enzastaurin, LY317615) was developed as a selective PKC $\beta$ inhibitor [1,2]. In cultured cancer cells, enzastaurin has antiproliferative and antiapoptotic activities [2]. Enzastaurin has antiangiogenic activity [3]. Enzastaurin also inhibits the AKT pathway with reduced phosphorylation of glycogen synthase kinase $3 \beta$ (GSK3- $\beta$ ) and AKT [2]. 
Vascular endothelial growth factor (VEGF) is a regulator of blood vessel growth [4]. Bevacizumab is a humanized anti-VEGF monoclonal antibody [4]. Because bevacizumab and enzastaurin mechanisms of action did not appear to overlap, we hypothesized that the combination might have additive or synergistic effects on tumors.

This study explored whether enzastaurin could be safely combined with bevacizumab in patients with advanced or metastatic cancer and evaluated preliminary antitumor activity of the combination. This study characterized enzastaurin pharmacokinetics (PK) when administered with bevacizumab. Enzastaurin was administered as in previous phase I studies and at higher doses and in different schedules than were previously used [5-9]. Based on known activity of bevacizumab in ovarian cancer (ovcar) [10], this study enrolled a large proportion of patients with the disease.

\section{Patients and methods}

\section{Eligibility}

Key eligibility criteria included histologic or cytologic diagnosis of advanced or metastatic cancer for which no preferable therapy existed; $\geq 18$ years of age; Eastern Cooperative Oncology Group (ECOG) performance status of 0 to 2 ; measurable or nonmeasurable disease as defined by Response Evaluation Criteria in Solid Tumors (RECIST version 1.0); [11] and an estimated life expectancy of $\geq 12$ weeks.

Key exclusion criteria included inability to swallow tablets; inability to discontinue phenytoin, carbamazepine, and phenobarbital; clinically significant cardiac disease; central nervous system metastases or tumor; evidence of bleeding diathesis or coagulopathy, or requirement for concurrent systemic anticoagulation; and history of major surgery, open biopsy, or significant traumatic injury within 28 days of treatment.

This study was conducted in accordance with the declaration of Helsinki and applicable good clinical practice guidelines. Human investigations were performed after approval by a local Human Investigations Committee and in accordance with an assurance filed with and approved by the Department of Health and Human Services. Written informed consent was obtained according to federal and local guidelines.

Study design and treatment

This was a single-center, open-label, nonrandomized, doseescalating phase I trial. The objectives were to: determine the recommended phase II doses (RP2D) of enzastaurin and bevacizumab; characterize toxicities; document antitumor activity; evaluate PK; and assess phosphorylated GSK3- $\beta$ (pGSK3- $\beta$ ) as a biomarker of enzastaurin. Because pharmacokinetic exposure variation was expected, cohorts of 6 were utilized. Planned enrollment was 66 patients.

Figure 1 shows the study design. Each cohort enrolled 3 patients; if $\leq 1$ dose-limiting toxicity (DLT) occurred, an additional 3 patients were enrolled in that cohort and dose escalation continued. The maximum tolerated dose (MTD) was achieved when 2 DLTs occurred in any given dose level; dose escalation then ceased, and the prior dose level was defined as the RP2D of the combination.

All patients continued on study drug therapy until progressive disease (PD), unacceptable toxicity, or other discontinuation criterion emerged. Once discontinued, patients were followed for 30 days following their last enzastaurin dose, or until they received another antitumor therapy.

\section{Patient evaluations}

Adverse events (AEs) were assessed using National Cancer Institute Common Terminology Criteria for Adverse Events (NCI CTCAE version 3.0) criteria. Hematologic DLTs were: grade 4 neutropenia for $\geq 7$ days; febrile neutropenia; and grade 3 thrombocytopenia with bleeding or grade 4 thrombocytopenia. Nonhematologic DLTs were: grade 3 or grade 4 toxicities; grade 4 hypertension; uncontrollable grade 3 hypertension; grade 4 hemorrhage; hemorrhage requiring discontinuation; any arterial thromboembolic event; grade 4 venous thrombosis; congestive heart failure; grade 4 proteinuria; gastrointestinal perforation, leak or fistula; grade 3 or grade 4 bowel obstruction; wound dehiscence requiring intervention; and grade 3 or 4 anaphylactic reactions to bevacizumab.

Tumor responses were assessed using RECIST guidelines [11]. Lesion assessments were repeated using the same methods as baseline. Tumor assessments by physical examination were performed prior to each cycle, whereas radiologic tumor assessments were done prior to every other cycle.

\section{Pharmacokinetic methods}

Plasma concentration-time data from intensive sampling were used to calculate PK parameters for enzastaurin and the major active metabolite LY326020 on cycle 2 day 1 and bevacizumab on cycle 1 day 1. Enzastaurin and LY326020 samples were analyzed at Advion BioServices, Inc. (Ithaca, NY) using validated tandem liquid chromatography mass spectrometry. Bevacizumab samples were analyzed at Intertek (ALTA Analytical Laboratory, San Diego, CA) using a validated enzyme-linked immunosorbent assay (ELISA).

Standard non-compartmental methods (WinNonlin ${ }^{\circledR}$ Enterprise, Version 5.3) were used to calculate PK parameters. 
The average concentration at steady state $\left(\mathrm{C}_{\mathrm{av}, \mathrm{ss}}\right)$ was determined for enzastaurin and LY326020. The area under the plasma concentration-versus-time curve from time zero to infinity $\left(\mathrm{AUC}_{[0-\infty]}\right)$ was determined for bevacizumab.

\section{Biomarker (GSK3- $\beta$ ) analysis}

Levels of pGSK3- $\beta$ in peripheral blood mononuclear cells (PBMCs) were measured using an ELISA assay by Millipore (Billerica, MA). The pGSK3- $\beta$ levels were normalized by the protein content of the sample.

\section{Statistical analysis}

Evaluation of RP2D was conducted for all patients receiving $\geq 1$ cycle of study medication and for patients who did not complete 1 cycle but experienced a DLT. Safety and PK analyses were performed for all patients receiving $\geq 1$ dose of study drug. Antitumor activity was described using best overall response and time to tumor progression (TTP). Kaplan-Meier survival functions were estimated. Changes in pGSK3- $\beta$ level from baseline were explored using a mixed-model repeated measures (MMRM) analysis with unstructured covariance to account for the within-patient correlation.

\section{Results}

\section{Patient characteristics}

From January 2007 to August 2009, 67 patients at Johns Hopkins Kimmel Cancer Center received $\geq 1$ dose of study drug. Table 1 shows baseline demographics.

\section{Safety}

The median delivered enzastaurin dose was $698 \mathrm{mg} / \mathrm{d}$ (range, 464 to $1938 \mathrm{mg} / \mathrm{d}$ ); this was $99 \%$ (range, $16 \%$ to $100 \%$ ) of the planned dose. The median bevacizumab dose was $10 \mathrm{mg} / \mathrm{kg}$ (range, 5 to 19); this was $100 \%$ of the planned dose. The mean \pm standard deviation number of received cycles was $8 \pm 10$.

Six patients experienced 1 DLT each during cycle 1. The DLTs were grade 3 fatigue $(n=4$; cohorts $2 \mathrm{c}, 2 \mathrm{~d}$, $3 \mathrm{~d})$, grade 4 cerebral hemorrhage $(n=1$; cohort $2 \mathrm{~b})$, and grade 3 elevated aspartate transaminase at dose level 2 $(n=1)$. Two patients in cohort $2 \mathrm{~d}$ experienced DLTs (grade 3 fatigue), thus defining the MTD. Consequently, the RP2 doses of enzastaurin were all preceding dose levels: $500 \mathrm{mg}$ QD or 250,375 , or $500 \mathrm{mg}$ BID, with bevacizumab $5 \mathrm{mg} / \mathrm{kg}$ or $10 \mathrm{mg} / \mathrm{kg}$ every 14 days, or $15 \mathrm{mg} / \mathrm{kg}$ every 21 days.
Eleven patients $(16.4 \%)$ experienced $\geq 1$ serious adverse event (SAE) that was considered drug-related (see Online Resource 1, footnote b). At least 66 patients experienced a drug-related AE. Drug-related AEs (all grades) occurring in $>20 \%$ of patients were: urine color change $(86.6 \%)$, fatigue $(68.7 \%)$, gastrointestinal other (52.2\%; mostly fecal discoloration), diarrhea (49.3\%), pain $(47.8 \%)$, nausea $(41.8 \%)$, pulmonary/ upper respiratory hemorrhage (31.3\%), constipation (29.9\%), anorexia (26.9\%), abdominal distention/bloating $(23.9 \%)$, and vomiting (20.9\%). Online Resource 1 shows drug-related grades 3 through 5 AEs.

Fourteen patients discontinued due to AEs, of which 12 were serious. Nine discontinuations were from drugrelated AEs, of which 7 were serious (grade 3 elevated aspartate transaminase and alanine transaminase; grade 4 cerebral hemorrhage; grade 3 failure to thrive; grade 4 genital tract fistula; grade 4 myocardial infarction; grade 3 thrombosis; and grade 3 pulmonary embolism). Each of the AEs and SAEs causing discontinuation occurred once. Six patients died during the trial; 2 deaths occurred on treatment, and 4 occurred within 30 days of treatment cessation. Of the 2 on-treatment deaths, 1 was from PD (cycle 4), and the second (ventricular tachycardia; cycle 1) was retrospectively considered possibly drug-related and confounded by PD. This patient with spinal involvement and potentially brain metastases, experienced a seizure-like situation and cardiac arrest with ventricular tachycardia on ECG. This event was not considered a DLT because the patient's disease had progressed, and death more likely stemmed from central nervous system involvement rather than from study drug. Of the 4 deaths occurring after treatment, 1 was thought to be bevacizumab-related (cerebral hemorrhage; cycle 1), and 3 were due to PD.

\section{Pharmacokinetics}

Table 2 shows the enzastaurin, LY326020, and bevacizumab PK results. When enzastaurin was administered as $500 \mathrm{mg}$ daily, the mean $C_{a v, s s}$ of enzastaurin and LY326020 were similar across bevacizumab schedules. A dose-dependent increase in the enzastaurin mean $\mathrm{C}_{\mathrm{av}, \mathrm{ss}}$ was seen across the 250- to 750-mg BID dose range when enzastaurin was given with 10 or $15 \mathrm{mg} / \mathrm{kg}$ bevacizumab.

The mean $\mathrm{AUC}_{(0-\infty)}$ for patients receiving bevacizumab $10 \mathrm{mg} / \mathrm{kg}$ ranged from $1740 \mu \mathrm{g} \cdot$ day $/ \mathrm{mL}$ to $2360 \mu \mathrm{g} \cdot$ day $/ \mathrm{mL}$,

\section{Efficacy}

Of the 67 enrolled patients, $19.4 \%$ (95\% confidence interval [CI], $10.8 \%$ to $30.9 \%$ ) responded to treatment (complete response, $9 \%$; partial response, $10.4 \%$ ) (Table 3). 


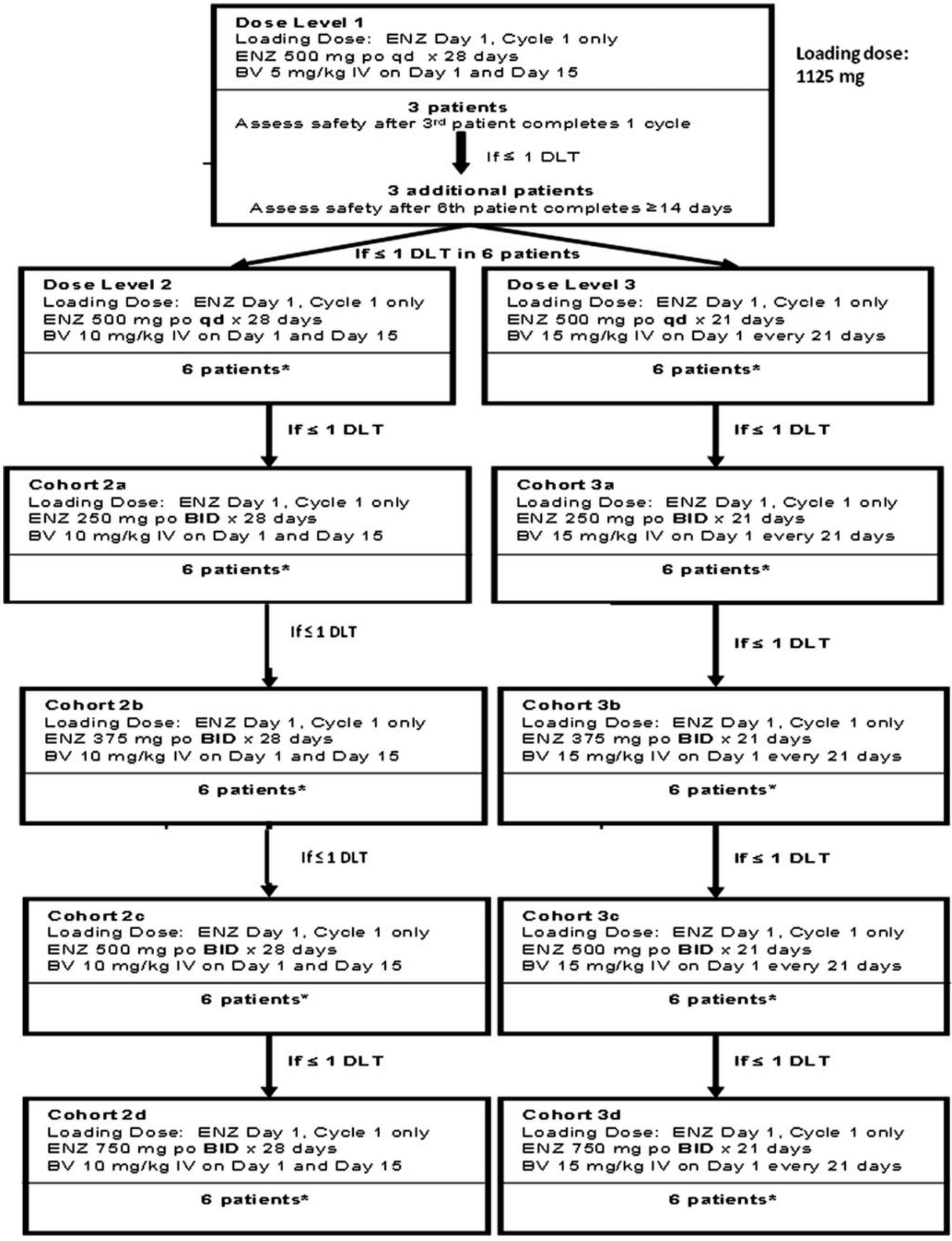


Fig. 1 Study design. Dosing of the cohorts is shown. BID, twice daily; BV, bevacizumab; DLT, dose-limiting toxicity; ENZ, enzastaurin; IV, intravenous; PO, oral; QD, once daily. * All cohorts subsequent to Dose Level 1 followed the same enrollment pattern and safety assessment schedule shown in Dose Level 1

Complete responses were experienced by patients with ovarian $(n=4)$, esophageal $(n=1)$, and neuroendocrine tumors $(n=1)$, and partial responses were experienced by patients with ovarian $(n=6)$ and uterine papillary $(n=1)$ cancers.

Table 3 also shows measured time to event parameters in the entire cohort and ovcar subgroup per dose level.

GSK3- $\beta$ analysis

PBMC samples from 54 treated patients were evaluable for pGSK3- $\beta$. Online Resource 2 shows estimated mean
pGSK3- $\beta$ over time by dose schedule, which suggests a decreasing trend of pGSK3- $\beta$ from baseline in both QD and BID schedules. However, the MMRM analysis did not suggest a statistically significant difference in pGSK- $\beta$ decline over time between the 2 dosing schedules.

\section{Discussion}

To determine the RP2D of enzastaurin and bevacizumab, this trial evaluated several dosing and scheduling regimens. Enzastaurin BID dosing was investigated because this schedule modestly increases exposures relative to QD dosing without clinically significant worsening of toxicities in most patients [6]. Oral enzastaurin (500 mg QD or 250,375 , or $500 \mathrm{mg}$ BID), together with bevacizumab $(5 \mathrm{mg} / \mathrm{kg}$ or $10 \mathrm{mg} / \mathrm{kg}$ every 14 days,
Table 1 Baseline patient demographics
ECOG Eastern Cooperative Oncology Group

\begin{tabular}{|c|c|c|}
\hline Characteristic & All Patients $(N=67)$ & Ovarian Cancer Subset $(n=31)$ \\
\hline Median age (range), years & $61.3(23.3$ to 84.6$)$ & $60.5(23.3$ to 73.7$)$ \\
\hline \multicolumn{3}{|l|}{ Gender } \\
\hline Female & $49(73.1)$ & $31(100.0)$ \\
\hline Male & $18(26.9)$ & - \\
\hline \multicolumn{3}{|l|}{ Origin } \\
\hline Caucasian & $59(88.1)$ & $26(83.9)$ \\
\hline African-American & $4(6.0)$ & $1(3.2)$ \\
\hline Asian & $1(1.5)$ & $1(3.2)$ \\
\hline Not reported/unknown & $3(4.5)$ & $3(9.7)$ \\
\hline \multicolumn{3}{|c|}{ ECOG Performance Status, n (\%) } \\
\hline 0 & $45(67.2)$ & $25(80.7)$ \\
\hline 1 & $22(32.8)$ & $6(19.3)$ \\
\hline \multicolumn{3}{|l|}{ Tumor type, n (\%) } \\
\hline Bladder & $3(4.5)$ & - \\
\hline Breast & $3(4.5)$ & - \\
\hline Esophagus & $2(3.0)$ & - \\
\hline Kidney & $2(3.0)$ & - \\
\hline Ovarian & $31(46.3)$ & $31(100.0)$ \\
\hline Parotid & $2(3.0)$ & - \\
\hline Peritoneal & $5(7.5)$ & - \\
\hline Prostate & $6(9.0)$ & - \\
\hline Uterine papillary & $2(3.0)$ & - \\
\hline Other & $11(16.4)$ & - \\
\hline \multicolumn{3}{|l|}{ Prior therapies, $\mathrm{n}(\%)$} \\
\hline At least 1 prior & $66(98.5)$ & $30(96.8)$ \\
\hline Surgery & $52(77.6)$ & $25(80.7)$ \\
\hline Radiotherapy & $16(23.9)$ & $1(3.2)$ \\
\hline Chemotherapy & $61(91.0)$ & $30(96.8)$ \\
\hline Immunotherapy & $6(9.0)$ & $1(3.2)$ \\
\hline Hormonal & $6(9.0)$ & $3(9.7)$ \\
\hline Supportive & $1(1.5)$ & $0(0.0)$ \\
\hline
\end{tabular}


Table 2 Pharmacokinetics of enzastaurin and bevacizumab

\begin{tabular}{|c|c|c|c|c|c|}
\hline Bevacizumab Dose & $5 \mathrm{mg} / \mathrm{kg}$ & \multicolumn{2}{|c|}{$10 \mathrm{mg} / \mathrm{kg}$} & \multicolumn{2}{|c|}{$15 \mathrm{mg} / \mathrm{kg}$} \\
\hline \multicolumn{6}{|l|}{$500 \mathrm{mg}$ QD } \\
\hline $\mathrm{N}$ & 3 & \multicolumn{2}{|l|}{$1^{\mathrm{a}}$} & \multicolumn{2}{|l|}{$2^{\mathrm{a}}$} \\
\hline Enzastaurin & $673(25)$ & \multicolumn{2}{|c|}{$393(\mathrm{NC})$} & \multicolumn{2}{|c|}{$1200,678(\mathrm{NC})$} \\
\hline LY326020 & $596(37)$ & \multicolumn{2}{|c|}{$744(\mathrm{NC})$} & \multicolumn{2}{|c|}{$609,718(\mathrm{NC})$} \\
\hline \multicolumn{6}{|l|}{$250 \mathrm{mg}$ BID } \\
\hline $\mathrm{N}$ & - & \multicolumn{2}{|l|}{6} & \multicolumn{2}{|l|}{4} \\
\hline Enzastaurin & - & \multicolumn{2}{|c|}{$557(117)$} & \multicolumn{2}{|c|}{$503(78)$} \\
\hline LY326020 & - & \multicolumn{2}{|c|}{$527(178)$} & \multicolumn{2}{|c|}{$812(61)$} \\
\hline \multicolumn{6}{|l|}{375 mg BID } \\
\hline $\mathrm{N}$ & - & \multicolumn{2}{|l|}{4} & \multicolumn{2}{|l|}{6} \\
\hline Enzastaurin & - & \multicolumn{2}{|c|}{$1030(66)$} & \multicolumn{2}{|c|}{$1110(112)$} \\
\hline LY326020 & - & \multicolumn{2}{|c|}{$1200(22)$} & \multicolumn{2}{|c|}{$1060(45)$} \\
\hline \multicolumn{6}{|l|}{$500 \mathrm{mg}$ BID } \\
\hline $\mathrm{N}$ & - & \multicolumn{2}{|l|}{4} & \multicolumn{2}{|l|}{4} \\
\hline Enzastaurin & - & \multicolumn{2}{|c|}{$1400(77)$} & \multicolumn{2}{|c|}{$1460(125)$} \\
\hline LY326020 & - & \multicolumn{2}{|c|}{$990(66)^{b}$} & \multicolumn{2}{|c|}{$1220(35)$} \\
\hline \multicolumn{6}{|l|}{750 mg BID } \\
\hline $\mathrm{N}$ & - & - & & 4 & \\
\hline Enzastaurin & - & - & & 2660 & \\
\hline LY326020 & - & - & & 1420 & \\
\hline Bevacizumab Exposure (Geon & Iean $[\mathrm{CV} \%])^{*}$ & & & & \\
\hline Enzastaurin Dosing Regimen & $500 \mathrm{mg}$ QD & $250 \mathrm{mg}$ BID & $375 \mathrm{mg}$ BID & 500 mg BID & 750 mg BID \\
\hline $\begin{array}{l}\text { Bevacizumab } 5 \mathrm{mg} / \mathrm{kg} \\
\mathrm{N}\end{array}$ & 6 & - & - & - & - \\
\hline $\mathrm{AUC}_{(0-\infty)}$ & $848(63)$ & - & - & - & - \\
\hline Bevacizumab $10 \mathrm{mg} / \mathrm{kg}$ & & & & & \\
\hline $\mathrm{N}$ & 6 & 6 & 3 & 5 & $2^{\mathrm{a}}$ \\
\hline $\mathrm{AUC}_{(0-\infty)}$ & $2360(17)$ & $1770(43)$ & $1740(5)$ & $1770(22)$ & $1570,1600(\mathrm{NC})$ \\
\hline Bevacizumab $15 \mathrm{mg} / \mathrm{kg}$ & & & & & \\
\hline $\mathrm{N}$ & 5 & 5 & 6 & 5 & 3 \\
\hline $\operatorname{AUC}_{(0-\infty)}$ & $2250(42)$ & $2590(45)$ & $1640(26)$ & $2080(25)$ & $1820(19)$ \\
\hline
\end{tabular}

$A U C_{(0-\infty)}$ area under the concentration-versus-time curve from zero to infinity; $B I D$ twice daily; $C_{a v, s s}$ average drug concentration at steady state; $C V$ coefficient of variation; $N$ number of patients with calculable estimates; $N C$ not calculable; $Q D$ once daily; (-) no data in group

* $\mathrm{C}_{\mathrm{av}, \mathrm{ss}}(\mathrm{nmol} / \mathrm{L})$ of enzastaurin and LY326020 from cycle 2, day 1 following once- or twice-daily dosing of enzastaurin with bevacizumab

**Bevacizumab $\mathrm{AUC}_{(0-\infty)}(\mu \mathrm{g} \cdot$ day $/ \mathrm{mL})$ estimates from cycle 1, day 1 following an intravenous infusion of bevacizumab with enzastaurin

${ }^{a}$ Insufficient data to calculate mean, individual parameter estimates listed

${ }^{\mathrm{b}} N=3$

or $15 \mathrm{mg} / \mathrm{kg}$ every 21 days) are well tolerated. The highest enzastaurin dose (750 $\mathrm{mg}$ BID) resulted in 4 DLTs (severe fatigue), with 2 occurring in cohort $2 \mathrm{~d}$ (Fig 1), thus defining the MTD.

The combination of enzastaurin and bevacizumab did not appear to alter or exacerbate the AE profiles that have been observed when either drug was given alone. The majority of enzastaurin-related AEs observed here were consistent with those observed in another enzastaurin monotherapy study
[5]. Other AEs were consistent with previous observations for bevacizumab [12].

The enzastaurin and LY326020 mean $\mathrm{C}_{\mathrm{av}, \mathrm{ss}}$ are similar to historical estimates for $250 \mathrm{mg}$ BID $(500 \mathrm{mg} / \mathrm{d})$ and $500 \mathrm{mg}$ QD [7,9]. This study showed no evidence that the $\mathrm{C}_{\mathrm{av} \text {,ss }}$ of enzastaurin or LY326020 were affected by bevacizumab $(5,10$, or $15 \mathrm{mg} / \mathrm{kg})$. Enzastaurinmean $\mathrm{C}_{\mathrm{av}, \mathrm{ss}}$ increases in a dose-dependent fashion when enzastaurin is dosed from $250 \mathrm{mg}$ to $750 \mathrm{mg}$ BID. 
Table 3 Summary of efficacy

\begin{tabular}{|c|c|c|c|c|c|c|}
\hline \multirow[t]{2}{*}{ Variable } & \multicolumn{3}{|c|}{ All Patients $(N=67)$} & \multicolumn{3}{|c|}{ Ovarian Cancer $(N=31)$} \\
\hline & $\begin{array}{l}\text { All } \\
N=67\end{array}$ & $\begin{array}{l}\text { QD } \\
n=18\end{array}$ & $\begin{array}{l}\text { BID } \\
n=49\end{array}$ & $\begin{array}{l}\text { All } \\
N=31\end{array}$ & $\begin{array}{l}\text { QD } \\
n=7\end{array}$ & $\begin{array}{l}\text { BID } \\
n=24\end{array}$ \\
\hline Response rate, $\mathrm{n}(\%)^{\mathrm{a}}$ & $13(19.4)$ & $6(33.3)$ & $7(14.3)$ & $10(32.3)$ & $4(57.1)$ & $6(25.0)$ \\
\hline $95 \% \mathrm{CI}^{\mathrm{b}}$ & 10.8 to 30.9 & 13.3 to 59.0 & 5.9 to 27.2 & 16.7 to 51.4 & 18.4 to 90.1 & 9.8 to 46.7 \\
\hline \multicolumn{7}{|l|}{ Best overall response, $\mathrm{n}(\%)$} \\
\hline Complete response & $6(9.0)$ & $5(27.8)$ & $1(2.0)$ & $4(12.9)$ & $3(42.9)$ & $1(4.2)$ \\
\hline Partial response & $7(10.4)$ & $1(5.6)$ & $6(12.2)$ & $6(19.4)$ & $1(14.3)$ & $5(20.8)$ \\
\hline Stable disease & $29(43.3)$ & $5(27.8)$ & $24(49.0)$ & $14(45.2)$ & $1(14.3)$ & $13(54.2)$ \\
\hline Progressive disease & $13(19.4)$ & $7(38.9)$ & $6(12.2)$ & $3(9.7)$ & $2(28.6)$ & $1(4.2)$ \\
\hline Not assessed & $12(17.9)$ & $0.0(0.0)$ & $12(24.5)$ & $4(12.9)$ & $0.0(0.0)$ & $4(16.7)$ \\
\hline Median duration of response (range), $\mathrm{mo}^{\mathrm{c}}$ & $\begin{array}{l}6.7 \\
(1.9 \text { to } 29.6)\end{array}$ & $\begin{array}{l}10.2 \\
(1.9 \text { to } 29.6)\end{array}$ & $\begin{array}{l}5.6 \\
(2.8 \text { to } 25.2)\end{array}$ & $\begin{array}{l}6.1 \\
(1.9 \text { to } 29.6)\end{array}$ & $\begin{array}{l}7.4 \\
\text { (1.9 to } 29.6)\end{array}$ & $\begin{array}{l}5.2 \\
(2.8 \text { to } 25.2)\end{array}$ \\
\hline $\begin{array}{l}\text { Median duration of stable disease } \\
\quad(95 \% \mathrm{CI}), \mathrm{mo}^{\mathrm{d}}\end{array}$ & $\begin{array}{l}3.7 \\
(2.8 \text { to } 4.1)\end{array}$ & $\begin{array}{r}2.8 \\
-\end{array}$ & $\begin{array}{l}3.7 \\
(2.8 \text { to } 4.1)\end{array}$ & $\begin{array}{l}3.9 \\
(3.7 \text { to } 5.5)\end{array}$ & - & $\begin{array}{l}4.0 \\
\text { (3.7 to } 11.3)\end{array}$ \\
\hline $\begin{array}{l}\text { 6-month rate of duration } \\
(95 \% \mathrm{CI})\end{array}$ & $\begin{array}{l}27.3 \\
(11.2 \text { to } 43.4)\end{array}$ & - & $\begin{array}{l}24.2 \\
(7.3 \text { to } 41.1)\end{array}$ & $\begin{array}{l}23.4 \\
(3.4 \text { to } 43.4)\end{array}$ & - & $\begin{array}{l}25.2 \\
\quad(3.8 \text { to } 46.6)\end{array}$ \\
\hline $\begin{array}{l}\text { Median time to disease progression or death } \\
(95 \% \mathrm{CI}), \mathrm{mo}^{\mathrm{e}}\end{array}$ & $\begin{array}{l}3.7 \\
(2.7 \text { to } 5.5)\end{array}$ & $\begin{array}{l}2.8 \\
(1.9 \text { to } 7.0)\end{array}$ & $\begin{array}{l}3.7 \\
(2.7 \text { to } 5.5)\end{array}$ & $\begin{array}{l}8.3 \\
(3.7 \text { to } 11.1)\end{array}$ & $\begin{array}{r}5.5 \\
-\end{array}$ & $\begin{array}{l}8.3 \\
(3.7 \text { to } 11.3)\end{array}$ \\
\hline 6-month TTP rate $(95 \% \mathrm{CI})$ & $\begin{array}{l}35.9 \\
\quad(23.9 \text { to } 47.9)\end{array}$ & $\begin{array}{l}38.9 \\
\quad(17.9 \text { to } 59.9)\end{array}$ & $\begin{array}{l}34.4 \\
\quad(20.3 \text { to } 48.5)\end{array}$ & $\begin{array}{l}50.4 \\
\quad(32.4 \text { to } 68.4)\end{array}$ & - & $\begin{array}{l}52.6 \\
\quad(32.0 \text { to } 73.2)\end{array}$ \\
\hline
\end{tabular}

$C I$ confidence interval; $C R$ complete response; $P D$ progressive disease; $P R$ partial response; $R E C I S T$ Response Evaluation Criteria in Solid Tumors; $S D$ stable disease

${ }^{a}$ Defined as the proportion of patients achieving a CR plus PR using RECIST version 1.0

${ }^{\mathrm{b}} 95 \%$ CI based on exact binomial probabilities

${ }^{\mathrm{c}}$ Measured from the date that measurement criteria are met for CR or PR until the first date of documented PD. Duration of response was censored at the date of the last assessment visit for responders with no evidence of PD

${ }^{\mathrm{d}}$ Measured from the date of the first dose until the first date of PD. Duration of SD was censored at the date of the last assessment visit for patients with SD with no evidence of PD

${ }^{\mathrm{e}}$ Defined as the time from the date of the first enzastaurin or bevacizumab dose to the first date of PD. Time to disease progression was censored at the date of the last assessment visit for patients with no evidence of PD. Estimated using the Kaplan-Meier method

Although $\mathrm{AUC}_{(0-\infty)}$ reported here for bevacizumab appears lower than in 2 historical studies [13, 14], no PK interaction is anticipated between enzastaurin and bevacizumab. Enzastaurin is primarily metabolized by CYP3A [5], whereas bevacizumab, a monoclonal antibody, is likely metabolized by the reticuloendothelial system[15]. The current study did not have a bevacizumab-only arm, so it is unknown whether the apparent difference in mean $\mathrm{AUC}_{(0-\infty)}$ is due to enzastaurin co-administration or simply a consequence of interstudy variability.

The response rate in this trial was higher than that reported in our previous phase I trial involving patients with advanced cancer [5]. Patients receiving BID treatment experienced a higher rate of disease stabilization than those receiving QD treatment, and patients with ovcar seemed to fare better than expected.

The combination of enzastaurin and bevacizumab was previously tested in a phase II trial involving patients with recurrent glioblastoma [16]. Although the combination was well tolerated and exhibited clinical activity, it did not appear to improve clinical outcomes relative to bevacizumab monotherapy. In contrast, the combination of enzastaurin and bevacizumab therapy appears to have delayed disease progression in the ovcar subset relative to results published for bevacizumab monotherapy [10, 17] and $500 \mathrm{mg}$ QD enzastaurin monotherapy in patients with ovcar [18]. This suggests that the combination may have a unique effect on ovarian tumors; however, it should be noted that the BID dosing schedule of enzastaurin may have provided an exposure advantage relative to the glioblastoma study, which used QD dosing [16]. The promising results for the ovcar subset should be viewed cautiously due to the small number of heterogeneous patients. Thus, further confirmatory studies are needed.

The activity of GSK3- $\beta$ is inhibited by PKB/AKT-dependent phosphorylation [19] and thus, is a potential biomarker of enzastaurin activity [2]. On average, pGSK3- $\beta$ levels were decreased from baseline in both schedules, with a maximum occurring at treatment discontinuation. However, no statistically 
significant difference in mean pGSK3- $\beta$ across time was found possibly related to large interpatient variability. The decline of pGSK3- $\beta$ levels with enzastaurin exposure time is consistent with previous findings, suggesting that the pGSK3- $\beta$ inhibitory effects in PBMCs are a component of the antitumor activity of enzastaurin [2]. The pGSK3- $\beta$ results are exploratory in nature and warrant further confirmatory studies.

In conclusion, this study showed no evidence that the PK of enzastaurin or LY326020 were affected when enzastaurin was administered with bevacizumab $(5,10$, or $15 \mathrm{mg} / \mathrm{kg})$. The observed antitumor activity in patients receiving both enzastaurin and bevacizumab was higher than that reported in our previous phase I trial involving patients with advanced cancer [5], with outcomes (median duration of stable disease; median TTP) appearing to favor the BID enzastaurin dosing groups. Combination therapy showed limited but potentially encouraging efficacy results in ovcar patients, but we cannot exclude the possibility that the observed activity is due to bevacizumab alone. The observed benefit should be confirmed in subsequent controlled trials and suggests that PI3K/AKT inhibition in combination with anti-VEGF therapy may be worth pursuing in patients with ovcar.

Acknowledgments The authors wish to acknowledge the patients, their families, and the study personnel who participated in this clinical trial, especially Melinda Downs, Rehab Abdallah, and Serina King. Avastin ${ }^{\circledR}$ (bevacizumab) was supplied by Genentech/Roche.

Ethical standards The clinical research described in this manuscript complies with all applicable international laws and national laws of the United States, where this research was conducted.

Conflicts of interest $\mathrm{M}$. Carducci received research funding from Eli Lilly and Company. D. Armstrong served on advisory boards for Genentech, supplier of bevacizumab. S. Ermisch, R. Decker, S. Nicol, and D. Thornton are employees of Eli Lilly and Company and own stock. J. Day and L. Kornberg are employees of PharmaNet/i3, which performs services for Eli Lilly and Company; J. Day owns Eli Lilly and Company stock.

N. Nwankwo, Z. Zhang, T. Wang, C. Collins, and L Resta declare no conflict of interest.

Disclosure statement This study was sponsored by Eli Lilly and Company.

Open Access This article is distributed under the terms of the Creative Commons Attribution License which permits any use, distribution, and reproduction in any medium, provided the original author(s) and the source are credited.

\section{References}

1. Faul MM, Gillig JR, Jirousek MR et al (2003) Acyclic N-(azacycloalkyl)bisindolylmaleimides: isozyme selective inhibitors of PKCbeta. Bioorg Med Chem Lett 13:1857-1859
2. Graff JR, McNulty AM, Hanna KR et al (2005) The protein kinase Cbeta-selective inhibitor, Enzastaurin (LY317615.HCl), suppresses signaling through the AKT pathway, induces apoptosis, and suppresses growth of human colon cancer and glioblastoma xenografts. Cancer Res 65:7462-7469

3. Keyes KA, Mann L, Sherman M et al (2004) LY317615 decreases plasma VEGF levels in human tumor xenograft-bearing mice. Cancer Chemother Pharmacol 53:133-140

4. Ferrara N, Hillan KJ, Gerber HP et al (2004) Discovery and development of bevacizumab, an anti-VEGF antibody for treating cancer. Nat Rev Drug Discov 3:391-400

5. Carducci MA, Musib L, Kies MS et al (2006) Phase I dose escalation and pharmacokinetic study of enzastaurin, an oral protein kinase $\mathrm{C}$ beta inhibitor, in patients with advanced cancer. $\mathrm{J}$ Clin Oncol 24:4092-4099

6. Hanauske A-R, Lahn M, Musib LC, Weigang-Kohler K et al (2009) Phase 1b safety and pharmacokinetic evaluation of daily and twice daily oral enzastaurin in combination with pemetrexed in advanced/metastatic cancer. Ann Oncol 20:1565-1575

7. Kreisl TN, Kim L, Moore K et al (2009) A phase I trial of enzastaurin in patients with recurrent gliomas. Clin Cancer Res 15:3617-3623

8. Rademaker-Lakhai JM, Beerepoot LV, Mehra N et al (2007) Phase I pharmacokinetic and pharmacodynamic study of the oral protein kinase $\mathrm{C}$ beta-inhibitor enzastaurin in combination with gemcitabine and cisplatin in patients with advanced cancer. Clin Cancer Res 13:4474-4481

9. Camidge DR, Gail ES, Gore L et al (2008) A phase I safety, tolerability, and pharmacokinetic study of enzastaurin combined with capecitabine in patients with advanced solid tumors. Anticancer Drugs 19:77-84

10. Burger RA, Sill MW, Monk BJ et al (2007) Phase II trial of bevacizumab in persistent or recurrent epithelial ovarian cancer or primary peritoneal cancer: a Gynecologic Oncology Group Study. J Clin Oncol 25:5165-5171

11. Therasse P, Arbuck SG, Eisenhauer EA et al (2000) New guidelines to evaluate the response to treatment in solid tumors. European Organization for Research and Treatment of Cancer, National Cancer Institute of the United States, National Cancer Institute of Canada. J Natl Cancer Inst 92:205-216

12. Gordon MS, Cunningham D (2005) Managing patients treated with bevacizumab combination therapy. Oncology 69(Suppl 3):25-33

13. Gordon MS, Margolin K, Talpaz M et al (2001) Phase I safety and pharmacokinetic study of recombinant human anti-vascular endothelial growth factor in patients with advanced cancer. J Clin Oncol 19:843-850

14. Wu JY, Wu XN, Ding L et al (2010) Phase I safety and pharmacokinetic study of bevacizumab in Chinese patients with advanced cancer. Chin Med J (Engl) 123:901-906

15. Shih T, Lindley C (2006) Bevacizumab: an angiogenesis inhibitor for the treatment of solid malignancies. Clin Ther 28:1779-1802

16. Moustakas A, Iwamoto FM, Kreisl TN et al (2010) Phase II trial of enzastaurin (Enz) with bevacizumab (BV) in adults with recurrent glioblastoma (GBM). J Clin Oncol 28(suppl): Abstract e12511

17. Cannistra SA, Matulonis UA, Penson RT et al (2007) Phase II study of bevacizumab in patients with platinum-resistant ovarian cancer or peritoneal serous cancer. J Clin Oncol 25:5180-5186

18. Usha L, Sill MW, Darcy KM et al (2011) A Gynecologic Oncology Group phase II trial of the protein kinase C-beta inhibitor, enzastaurin and evaluation of markers with potential predictive and prognostic value in persistent or recurrent epithelial ovarian and primary peritoneal malignancies. Gynecol Oncol 121:455-461

19. Liang J, Slingerland JM (2003) Multiple roles of the PI3K/ PKB (Akt) pathway in cell cycle progression. Cell Cycle 2:339-345 